\title{
Environmental management and green brand for sustainable entrepreneurship
}

\author{
Luidmula Starchenko ${ }^{1}$, Serhiy Lyeonov ${ }^{2}$, Tetyana Vasylieva $^{3}$, Tetyana Pimonenko ${ }^{4 *}$, and Oleksii Lyulyov $^{4}$ \\ ${ }^{1}$ Sumy State University, Department of Economics, Entrepreneurship and Business Administration, Ukraine \\ ${ }^{2}$ Sumy State University, Department of Cyber Security, Ukraine \\ ${ }^{3}$ Sumy State University, Department of Finance and Entrepreneurship, Ukraine \\ ${ }^{4}$ Sumy State University, Department of Marketing, Ukraine
}

\begin{abstract}
The increasing competitiveness at the global market and reinforcing the ecological issues contribute the reorientation from the traditional to the sustainable business model. In this case, the business should develop the green brand of the company, which required the implementation of environmental management. The hypothesis of the paper is checking the linking between environmental management and green brand at the company. The results of bibliometrics analysis on the selected theme confirmed the increasing numbers of papers which focused on analysing the relationships between the efficiency of environmental management and green brand at the company. In the paper, the authors used the VosViewer with the purpose to visualise the main scientific patterns on the selected theme. At the second stage, the authors identified the relationships between green brand and environmental management at the company using the ANOVA model. The data for analysis was obtained from the questionaries among companies management (which promote as green companies) and companies' financial statements. The two indicators described the green brand: loyalty to the green brand (frequency of searching company's brand in Google); net profit. The findings proved that companies with effective environmental management had a higher net profit and loyalty to the green brand.
\end{abstract}

\section{Introduction}

The current trend of strengthening the ecological issues, promoting of Sustainable Development Goal 2030, increasing of global competitiveness provokes from the company the appropriate adaptations and changes considering the new trends. Thus, if companies wish to fix a stable position in the worldwide market, higher management should develop and implement the sustainable entrepreneurship model. It means that management should implement an environmentally responsible policy considering the main principles of sustainable development. Besides, the world-leading companies refused to work with the none ecological responsible companies which functioning without environmental management. Thus, the companies should reorient from eco destructive to sustainable entrepreneurship model. The findings proved that most investigations of the green brand and environmental management focused on the qualitative analysis without empirical confirmation.

\section{Literature Review}

The finding of the bibliometric analysis showed the increasing numbers of papers in Scopus which analysed sustainable entrepreneurship, green brand and environmental management from the 1991 year. The authors of the most cited paper [1] in Scopus (404 citations) confirmed that the marketing instruments to promote green brand had a positive effect on implementing the greener patterns of consumptions and productions. At the same time, the scientists in the paper $[2-8,9]$ confirmed the hypothesis that sustainable entrepreneurship could not be realised without developing the green brand, effective environmental management, implementation of green innovations. The authors in the papers $[10,11]$ confirmed the hypothesis that an effective system of environmental management could increase the company's performance.

Besides, the authors proved that sustainable entrepreneurship model allowed to increase the company's profit. The co-citation analysis allowed allocating of four clusters of scientist which analysed the selected issues (Fig. 1). The results showed that scientists from the United Kingdom, the United States of America and China published the vast numbers of the documents on the chosen theme (Fig. 2).

The findings proved that developing sustainable entrepreneurship relates to the range of factors: leadership [12, 13]; communications with stakeholders [14, 15]; institutional development and green innovation technologies [16-22]; developing of bank sector [23-27];

\footnotetext{
Corresponding author: tetyana_pimonenko@econ.sumdu.edu.ua
} 
country's brand [28]; macroeconomic stability [29-32]; ecological security $[33,34]$.

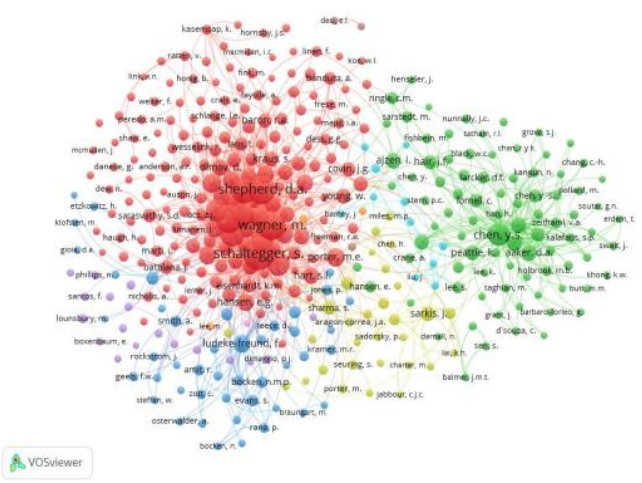

Fig. 1. The visualising of co-citation analysis of the scientists which investigated the sustainable entrepreneurship, green brand and environmental management

Source: developed by the authors using VOSviewer

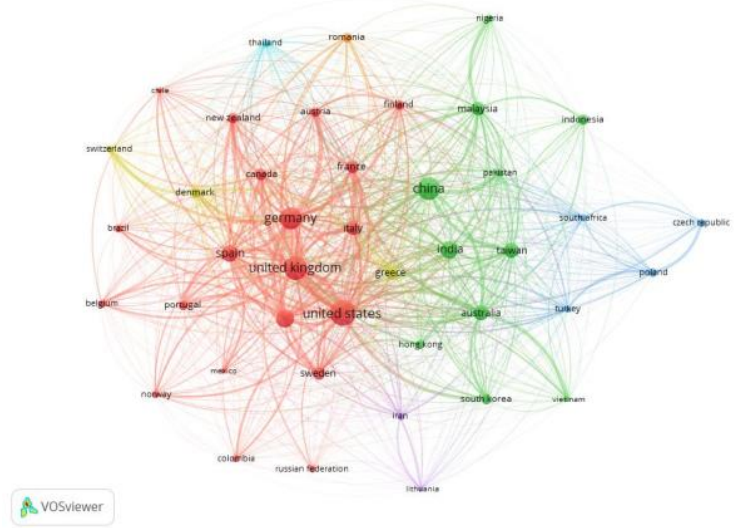

Fig. 2 The visualising of cross-countries analysis of the scientists which investigated the sustainable entrepreneurship, green brand and environmental management

Source: developed by the authors using VOSviewer

The scientists in the paper [35] confirmed that sustainable development could not be realised without green investment. It allowed boosting the green entrepreneurship.

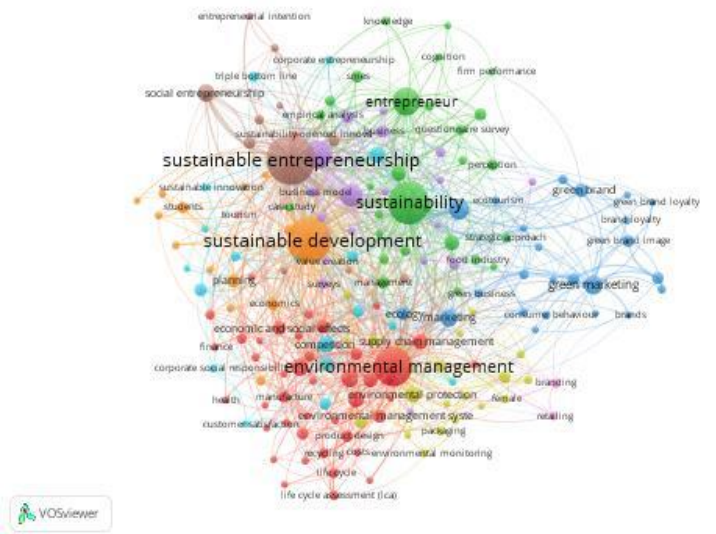

Fig. 3. The visualising of bibliometric analysis of the papers which focused on sustainable entrepreneurship, green brand and environmental management

Sources: developed by the authors using VOSviewer
The visualising of findings of the bibliometrics analysis allowed identify the eight scientific patterns on investigation the sustainable entrepreneurship (Fig. 3).

The first patterns (red) focused on analysing environmental management and contained 43 items. The second patterns (green) compiled the green economy and sustainability issues. The third patterns (blue) focused on investigating the green brand and marketing instruments. The next patterns (brown and orange) focused on analysing the principles of sustainable entrepreneurship and sustainable development. Besides, the brown patterns had the most significant numbers of links 177, which proved the analysis of sustainable entrepreneurship from different points of views. At the same time, most of the investigations had qualitative characters without empirical justification. In this case, it is necessary to do the empirical analysis of the green brand and environmental management as a core element of sustainable entrepreneurship.

\section{Research methods}

The general hypothesis of the paper was:

$\mathrm{H}$ : exists the linking between the green brand and environmental management at the company.

For the analysis, the sub hypothesis was allocated. The model of the investigation was presented in Fig. 4.

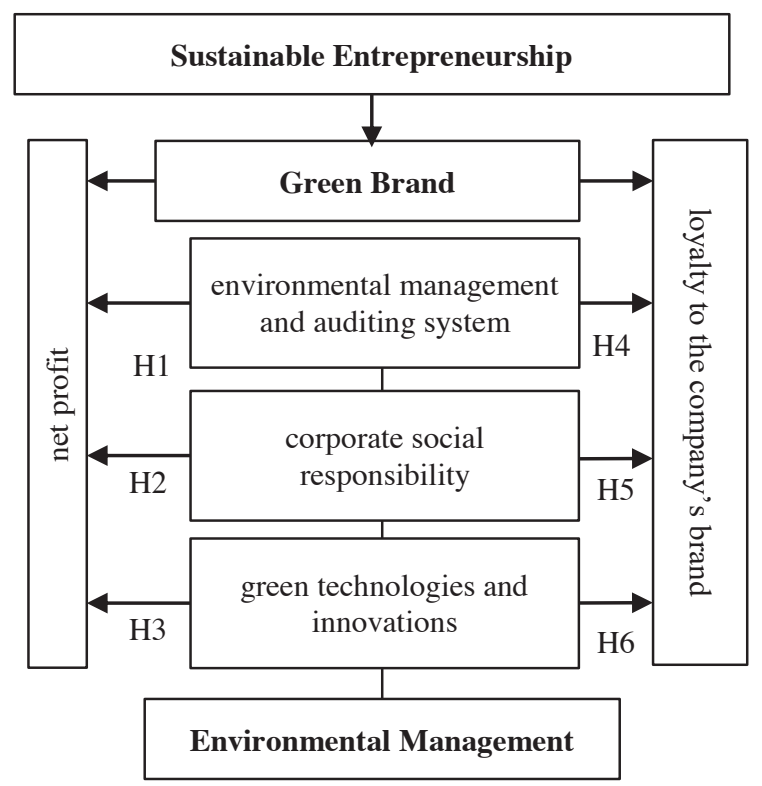

Fig. 4. The hypothesis of the investigation Source: developed by the authors

The authors have chosen 150 Ukrainian companies for analysis which promotes itself as green companies. In the paper, the questionaries used for analysis the role and the efficiency of environmental management at the companies. Based on the findings of bibliometrics analyses the authors allocated the three indicators which described the efficiency of environmental management: implementation of environmental management and auditing system; implementation of corporate social responsibility; providing of green technologies and 
innovations. These indicators become the basis of the questionaries and measured by the 5-point Likert scale.

The authors estimated the green brand by two parameters: net profit (financial statements of the company); loyalty to the company's brand (frequency of searching the company's brand in Google). Three groups classified all companies relate on the scale (quantity of the workers and income): small; middle; large. The testing of the significant impact of environmental management on a green brand was done by using the ANOVA model. It technique allowed identifying the most significant variable among the analysis parameters.

\section{Results}

At the first step, the comparison of the companies scale for environmental management and the green brand was made. The results of the analysis showed in Table 1.

Table 1. Comparison of companies scale for Environmental management and Green Brand

\begin{tabular}{|c|c|c|c|}
\hline \multirow{2}{*}{ Variables } & \multicolumn{3}{|c|}{ Mean for } \\
\hline & small & medium & large \\
\hline \multicolumn{4}{|c|}{ Environmental management } \\
\hline $\begin{array}{l}\text { environmental } \\
\text { management and auditing } \\
\text { system (EMAS) }\end{array}$ & 2.344 & 4.543 & 3.499 \\
\hline $\begin{array}{l}\text { corporate } \\
\text { responsibility (CSR) }\end{array}$ & $3.212 *$ & 4.332 & 4.855 \\
\hline $\begin{array}{l}\text { green technologies and } \\
\text { innovations (GTI) }\end{array}$ & 4.445 & 4.765 & 4.785 \\
\hline \multicolumn{4}{|c|}{$\begin{array}{ll}\text { Green Brand } \\
\end{array}$} \\
\hline Net profit (NP) & 4.345 & 45.432 & 55.526 \\
\hline $\begin{array}{l}\text { Loyalty to the company's } \\
\text { brand (L) }\end{array}$ & 1323.12 & 1432.22 & 1987.34 \\
\hline
\end{tabular}

Considering the finding, the non-significance variables were corporate social responsibility for small companies. Besides, on environmental management, the highest value for small companies were green technologies, for medium - green technologies and innovations, for large - corporate social responsibilities. At the next stage, the authors provided the ANOVA test (Table 2).

ANOVA test allowed identifying the significant factors which influenced the measures of the green brand. The findings confirmed the differences between the selected group of indicators for all analysed companies. It allowed concluding that analysed companies with environmental management have the highest net profit and loyalty to the green brand.

The statistically significant difference between analysed groups for large, medium and small companies for all findings were $0.01 \mathrm{~m}$ level. Besides, the corporate social responsibility (CSR) had significant differences in net profit at level 0.10 for large companies and significant for loyalty to the company's brand at level 0.10 for medium and small companies.
Table 2. The findings of the ANOVA test

\begin{tabular}{|c|c|c|c|c|}
\hline \multicolumn{3}{|c|}{ Variables } & \multirow{2}{*}{ F-value } & \multirow{2}{*}{ p-value } \\
\hline & Dependent & Test & & \\
\hline \multirow{7}{*}{$\sum_{\infty}^{3}$} & EMAS & \multirow{4}{*}{ NP } & 5.03 & $0,004 *$ \\
\hline & CSR & & 4.52 & $0,001 *$ \\
\hline & GTI & & 8.42 & $0,000 *$ \\
\hline & ISO & & 3.54 & $0,000 *$ \\
\hline & EMAS & \multirow{3}{*}{$\mathrm{L}$} & 2.36 & $0,000 *$ \\
\hline & CSR & & 8.37 & $0,035 * *$ \\
\hline & GTI & & 3.45 & $0,000^{*}$ \\
\hline \multirow{7}{*}{ 竞 } & EMAS & \multirow{4}{*}{ NP } & 5. & $0,001 *$ \\
\hline & CSR & & 4.46 & $0,000 *$ \\
\hline & GTI & & 2.36 & $0,003 *$ \\
\hline & ISO & & 4.56 & $0,000 *$ \\
\hline & EMAS & \multirow{3}{*}{$\mathrm{L}$} & 2.45 & $0,000 *$ \\
\hline & CSR & & 3.47 & $0,045 * *$ \\
\hline & GTI & & 3.36 & $0,000^{*}$ \\
\hline \multirow{6}{*}{ 聅 } & EMAS & \multirow{3}{*}{ NP } & 4.56 & $0,000^{*}$ \\
\hline & CSR & & 2.24 & $0,066 * *$ \\
\hline & GTI & & 4.46 & $0,000^{*}$ \\
\hline & EMAS & \multirow{3}{*}{$\mathrm{L}$} & 3.44 & $0,000^{*}$ \\
\hline & CSR & & 4.56 & $0,001 *$ \\
\hline & GTI & & 2.45 & $0,000 *$ \\
\hline
\end{tabular}

\section{Conclusions}

The findings of bibliometrics analysis proved the increasing interests on the investigation of relationships between green brand and environmental management as the core elements of the sustainable entrepreneurship. The result allowed identifying the scientific patterns (environmental management; green economy; green brand and marketing instruments) on investigating the issues as mentioned above. The scientists from the United Kingdom, United States and Chine made a significant impact in the investigation on sustainable entrepreneurship from different points of views.

The results of the ANOVA test confirmed statistically significant differences between analysed groups of the parameters. It allowed confirming the hypothesis that environmental management had a statistically significant impact on the green brand.

\section{Funding}

This research was funded by the grant from the Ministry of Education and Science of Ukraine (Nos. g/r 0120U102002, 10117U003932, 0120U102001).

\section{References}

1. J. Pickett-Baker, R. Ozaki. Pro-environmental products: Marketing influence on consumer purchase decision. Journal of Consumer Marketing. 25 (2008). 
2. T. J. Dean, J. S. McMullen. Toward a theory of sustainable entrepreneurship: Reducing environmental degradation through entrepreneurial action. Journal of Business Venturing. 22, 50-76 (2007).

3. Y.S. Chen, The drivers of green brand equity: Green brand image, green satisfaction, and green trust. Journal of Business Ethics. 93, 307-319 (2010).

4. Y.C. Huang, M. Yang, Y. C. Wang, Effects of green brand on green purchase intention. Marketing Intelligence and Planning. 32, 250-268 (2014)

5. N. Mohd Suki, Green product purchase intention: impact of green brands, attitude, and knowledge. British Food Journal. 118, 2893-2910 (2016).

6. J. K. Hall, G. A. Daneke, M. J. Lenox, Sustainable development and entrepreneurship: Past contributions and future directions. Journal of Business Venturing. 25, 439-448 (2010).

7. S. Schaltegger, M. Wagner, Sustainable entrepreneurship and sustainability innovation: Categories and interactions. Business Strategy and the Environment. 20, 222-237 (2011).

8. J. Gast, K. Gundolf, B. Cesinger, Doing business in a green way: A systematic review of the ecological sustainability entrepreneurship literature and future research directions. Journal of Cleaner Production. 147 (2017), pp. 44-56

9. P. Bhandari Medani Sustainable Development: Is This Paradigm The Remedy of All Challenges? Does Its Goals Capture The Essence of Real Development and Sustainability? With Reference to Discourses, Creativeness, Boundaries and Institutional Architecture. SocioEconomic Challenges, 3(4), 97128 (2019).

10. F. D., Tommaso, A., Gulinelli, Corporate Governance and Economic Performance: The Limit of Short Termism. Financial Markets, Institutions and Risks, 3(4), 49-61 (2019).

11. K., Kasztelnik, V. W. Gaines, Correlational Study: Internal Auditing and Management Control Environment Innovation within Public Sector in the United States. Financial Markets, Institutions and Risks, 3(4), 5-15 (2019).

12. G., Thomas. Leadership Models and Leadership Styles as Success Factors in Small and Mediumsized Enterprises. Business Ethics and Leadership, 4(1), 35-42, (2020).

13. T., Goncharenko. From Business Modelling to the Leadership and Innovation in Business: Bibliometric Analysis (Banking as a Case). Business Ethics and Leadership, 4(1), 113-125, (2020).

14. Vasilieva, T., Lieonov, S., Makarenko, I., \& Sirkovska, N. Sustainability information disclosure as an instrument of marketing communication with stakeholders: markets, social and economic aspects. Marketing and Management of Innovations, 350-357 (2017).
15. F., Wang, J., Lo, M.Lam. Mediating Effects of Stakeholders and Supervision on Corporate Social Responsibility. Business Ethics and Leadership, 4(1), 43-56, (2020).

16. S., Hasan, P., Dutta. Coverage of Environmental Issues in Local Dailies of Chattogram Centering World Environment Day. SocioEconomic Challenges, 3(4), 63-71 (2019).

17. V. Pavlyk Institutional Determinants Of Assessing Energy Efficiency Gaps In The National Economy. SocioEconomic Challenges, 4(1), 122128 (2020).

18. A., Masharsky, G.,Azarenkova, K., Oryekhova, S., Yavorsky. Anti-crisis financial management on energy enterprises as a precondition of innovative conversion of the energy industry: case of Ukraine. Marketing and Management of Innovations, (3), 345-354 (2018).

19. H., Dkhili. Environmental performance and institutions quality: evidence from developed and developing countries. Marketing and Management of Innovations, (3), 333-344 (2018)

20. A. Kwilinski, Mechanism of modernisation of industrial sphere of industrial enterprise in accordance with requirements of the information economy. Marketing and Management of Innovations . 4, 116-128 (2018).

21. Y. Yevdokimov, O. Chygryn, T. Pimonenko, O. Lyulyov, Biogas as an alternative energy resource for Ukrainian companies: EU experience. Innovative Marketing. 14, 7-15 (2018)

22. I. Kendiukhov, M. Tvaronavičienè, Managing innovations in sustainable economic growth. Marketing and Management of Innovations, 33-42 (2017).

23. Y. Bilan, S. Lyeonov, T. Vasylieva, Y. Samusevych, Does tax competition for capital define entrepreneurship trends in Eastern Europe? Online Journal Modelling the New Europe, 34-66 (2018).

24. A. GrenÄÃ kovÃ $i$, Y. Bilan, Y. Samusevych, A. Vysochyna, in Proceedings of the 33rd International Business Information Management Association Conference, IBIMA 2019: Education Excellence and Innovation Management through Vision 2020 (International Business Information Management Association, IBIMA, 2019), pp. 25362547

25. O. Kuzmenko, S. Kyrkach, The use of regression analysis in the financial planning of banks, mathematical formalisation of the stages of financial planning in banks. Banks and Bank Systems. 9, 120126 (2014).

26. K. Djalilov, T. Vasylieva, S. Lyeonov, A. Lasukova, Corporate social responsibility and bank performance in transition countries. Corporate Ownership and Control. 13, 879-888 (2015).

27. Y. Bilan, Đ. Đšuzmenko, A. Boiko, in Proceedings of the 33rd International Business Information 
Management Association Conference, IBIMA 2019:

Education Excellence and Innovation Management through Vision 2020 (International Business Information Management Association, IBIMA, 2019), pp. 2373-2384.

28. Y. Bilan, S. Lyeonov, O. Lyulyov, T. Pimonenko, Brand management and macroeconomic stability of the country. Polish Journal of Management Studies. 19, 61-74 (2019).

29. Y. Bilan, T. Vasilyeva, O. Lyulyov, T. Pimonenko, EU vector of Ukraine development: Linking between macroeconomic stability and social progress. International Journal of Business and Society. 20, 433-450 (2019).

30. Y. Bilan, T. Pimonenko, L. Starchenko, in E3S Web of Conferences (EDP Sciences, 2020), vol. 159.

31. O. Lyulyov, H. Shvindina, Stabilisation Pentagon Model: Application in the management at macro- and micro-levels. Problems and Perspectives in Management. 15, 42-52 (2017).

32. Ibragimov, Z., Vasylieva, T., \& Lyulyov, O. (2019). The national economy competitiveness: effect of macroeconomic stability, renewable energy on economic growth. Economic and Social Development: Book of Proceedings, 877-886.

33. G. Mentel, T. Vasilyeva, Y. Samusevych, S. Pryymenko, Regional differentiation of electricity prices: Social-equitable approach. International Journal of Environmental Technology and Management. 21, 354-372 (2018).

34. L. F. Sokolenko, I. V. Tiutiunyk, D. V. Leus, Ecological and economic security assessment in the system of regional environmental management: A case study of Ukraine. International Journal of Ecology and Development. 32, 27-35 (2017).

35. V., Pavlyk, Assessment of green investment impact on the energy efficiency gap of the national economy. Financial Markets, Institutions and Risks, 4(1), 117-123 (2020). 